ARTIGO ORIGINAL

\title{
Propriedades físicas e químicas da madeira de Pinus elliottii impregnada com sílica
}

\author{
Physical and chemical properties of Pinus elliottii wood impregnated with silica \\ Paulo Rovedder Júnior ${ }^{1}$ (D), Andrey Pereira Acosta ${ }^{1}$ (D), Henrique Römer Schulz ${ }^{1}$ (D), Ezequiel Gallio ${ }^{1}$ (D), \\ Darci Alberto Gatto ${ }^{1}$ (D) \\ ${ }^{1}$ Universidade Federal de Pelotas - UFPEL, Pelotas, RS, Brasil
}

\begin{abstract}
Como citar: Rovedder Júnior, P., Acosta, A. P., Schulz, H. R., Gallio, E., Gatto, D. A. (2021). Propriedades físicas e químicas da madeira de Pinus elliottii impregnada com sílica. Scientia Forestalis, 49(130), e3478. https://doi.org/10.18671/scifor.v49n130.24
\end{abstract}

\begin{abstract}
Resumo
O objetivo do presente trabalho foi realizar a caracterização tecnológica de madeira Pinus elliottii impregnada com sílica extraída a partir da casca do arroz, em diferentes concentrações (1\% e 2\%). A sílica foi caracterizada por granulometria, espectroscopia no Infravermelho por Transformada de Fourier (FT-IR), difração de raios x (DRX) e rendimento. Empregou-se o método de vácuo-pressão para o tratamento da madeira. As propriedades físicas analisadas após os tratamentos foram, massa específica aparente $(\rho 12)$ e básica $(\rho b)$, teor de umidade (Tu), ganho de massa (PMG), taxa de absorção de água (TAA), absorção de água (A.A.) e propagação de chamas. A análise de espectroscopia no infravermelho (FTIR) comprovou a impregnação da sílica, com base nas bandas 700 e $2920 \mathrm{~cm}^{-1}$ que obtiveram redução de seus picos com o tratamento. Os resultados obtidos para ganho de massa com a impregnação da sílica assim como as massas específica básica e aparente, não obtiveram valores significativos, para os dois tratamentos, $1 \%$ e $2 \%$. As madeiras tratadas apresentaram maior taxa de absorção de água 2,1 g/h para (T1\%), 2,24 g/h (T2\%) enquanto o controle 1,6 g/h. A absorção de água demonstrou uma inversão das madeiras tratadas para o controle na hora 17, onde o controle passou a absorver mais água. As propriedades mecânicas não obtiveram resultados estatisticamente significativos. Na propagação de chamas o tratamento com sílica se mostrou eficiente, aumentando o tempo para atingir $20 \%$ da massa da amostra em 4,7 vezes, especialmente o tratamento com $2 \%$ de sílica.
\end{abstract}

Palavras-chave: Sílica; FT-IR; DRX; Propriedades físicas; Propagação de chamas.

\begin{abstract}
The objective of the present work was to perform the technological characterization of Pinus elliottii wood impregnated with silica extracted from rice husks in different concentrations ( $1 \%$ and $2 \%)$. Silica was characterized by particle size, Fourier Transform Infrared (FT-IR) spectroscopy, X-ray diffraction (XRD) and yield. The vacuum-pressure method was used to treat the wood. The physical properties analyzed after the treatments were apparent bulk ( $\rho 12)$ and basic $(\rho b)$, moisture content (Tu), mass gain (PMG), water absorption rate (TAA), water absorption (A.A.) and flame spread. Infrared spectroscopy (FTIR) analysis confirmed the impregnation of silica, based on the 700 and $2920 \mathrm{~cm}^{-1}$ bands that reduced their peaks with the treatment. The results obtained for mass gain with silica impregnation as well as the basic and apparent specific masses did not yield significant values for both treatments, $1 \%$ and $2 \%$. The treated woods presented higher water absorption rate 2,1 g/h for (T1\%), 2,24 g/h (T2\%) than the control 1,6 g/h. Water absorption demonstrated a reversal of the treated woods to the control at hour 17, where the control began to absorb more water. The mechanical properties did not yield statistically significant results. With flame propagation silica treatment proved to be efficient, increasing the time to reach $20 \%$ of the sample mass by 4,7 times, especially in the $2 \%$ silica treatment.
\end{abstract}

Keywords: Silica; FT-IR; DRX; Physical properties; Flame spread.

Fonte de financiamento: None.

Conflito de interesse: None.

Autor correspondente: paulorovedder@hotmail.com

Recebido: 25 setembro 2019.

Aceito: 15 julho 2020.

Editor: Paulo Henrique Müller Silva.

(c) (i) Este é um artigo publicado em acesso aberto (Open Access) sob a licença Creative Commons Attribution, que permite uso, distribuição e

c) reprodução em qualquer meio, sem restrições desde que o trabalho original seja corretamente citado. 


\section{INTRODUÇÃO}

O uso de espécies de rápido crescimento podem ser um meio alternativo de aumentar o suprimento de madeira e proteger os recursos naturais da superexploração (Ayrilmis \& Kaymakci, 2013). Normalmente, as espécies de rápido crescimento produzem uma grande proporção de madeira juvenil quando plantadas em países tropicais, o que representa um grande desafio para programas avançados de melhoramento para controle de qualidade da madeira (Acosta et al., 2020). Dentre as espécies cultivadas, no Brasil destaca-se o Pinus elliottii, sendo gerador de madeira de boa qualidade empregada para a produção de resina, madeira serrada, madeira roliça para postes e mourões, indústrias de polpa e papel e chapas (Cademartori et al., 2012). No entanto esta espécie possui certas características que limitam sua aplicação, como a instabilidade dimensional, baixa estabilidade térmica e resistência mecânica, se comparada à outras espécies de reflorestamento como o gênero Eucalyptus.

Assim, inúmeros tratamentos foram testados com sucesso nas últimas décadas, os quais se dividem em três categorias: modificação química, impregnação e modificação térmica (Rowell, 2012). A modificação por impregnação consiste na inserção particulas no interior da madeira produzindo um preenchimento dos espaços vazios na madeira.

A silicificação por sua vez é um dos processos de impregnação menos nocivos ao meio ambiente, consistindo na cristalização do lúmen da madeira, aumentando a sua dureza e melhorando a resistência contra produtos químicos, processos biológicos e intempéries (Götze et al., 2008). Tal processo é obtido por meio da utilização de sílica, adquirida a partir de uma matéria prima de baixo custo e de fácil obtenção uma vez que pode ser originado de vegetais em abundância, como a cavalinha (Equisetum arvenses $L$.) e a casca do arroz.

Para a produção da sílica é utilizada a casca do arroz sendo uma iniciativa vantajosa, uma vez que a região sul do Brasil é favorecida pela presença de indústrias atuantes no refino e processamento de arroz gerando toneladas de casca como resíduo, que não têm aproveitamento. Aliado a isso, o Pinus elliottii apresenta características ideais para o processo de silicificação por se tratar de uma madeira com alta porosidade, facilitando o fluxo da solução contendo sílica no interior da madeira. Neste contexto, utilizando matérias-primas sustentáveis e renováveis, o trabalho objetivou a obtenção de silica da casca de arroz por calcinação a $700^{\circ} \mathrm{C}$ e a utilização da mesma no tratamento da madeira de Pinus elliottii em dois distintos percentuais (1 e $2 \%$ ).

\section{MATERIAL E MÉTODOS}

\section{Matéria Prima}

\section{Obtenção da sílica e corpos de prova}

Realizou-se a extração da sílica a partir da casca de arroz, conforme Nicacio (2017). Para se obter o máximo de pureza nas partículas de sílica realizou-se tratamentos térmicos e químicos. Para eliminar impureza metálicas, assim como possíveis resíduos de terra e poeira, foi realizado tratamento na casca de arroz com ácido clorídrico $(\mathrm{HCl})$. Este tratamento constituiu em adicionar 600 gramas de casca de arroz, estabilizadas em câmara climática a $20^{\circ} \mathrm{C}$ de temperatura e $65 \%$ de umidade relativa, juntamente com $4000 \mathrm{ml}$ de solução aquosa de $5 \%$ de ácido clorídrico. O material foi disposto em frasco de Erlenmeyer por um período de 90 minutos a $120{ }^{\circ} \mathrm{C}$ e $10 \mathrm{Kgf} / \mathrm{cm}^{2}$ em ebulição na autoclave vertical (Phoenix Luferco AV), método semelhante a Fernandes et al., (2014).

Após o processo em autoclave as cascas de arroz foram lavadas com água destilada a fim de estabilizá-las, até atingirem um pH entre 5 e 7, então foram encaminhadas para estufa a $100 \pm 2{ }^{\circ} \mathrm{C}$ durante 48 horas para a remoção total da água nas cascas.

Com a remoção total da água nas cascas de arroz realizou-se o trituramento no moinho de bolas (Matoli 070M001) com potência de $180 \mathrm{~W}$, cada batelada de 60 minutos com 15 gramas da casca de arroz (tratada) a fim de conseguir granulometria micrométrica. 
Em seguida, as partículas foram dispostas em dois cadinhos de $100 \mathrm{ml}$ contendo cada um 30g, foram calcinadas em mufla (Magnu's) a $700{ }^{\circ} \mathrm{C}$ durante 90 minutos para eliminação total da parte orgânica, com isso, o material resultante é em sua maioria partículas de sílica, $\mathrm{SiO}_{2}$.

Utilizou-se a madeira de Pinus elliottii Engelm. com cerca de 20 anos, provenientes de um

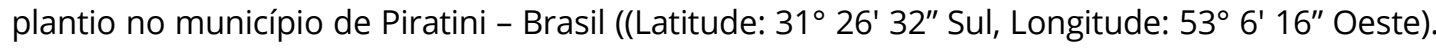
Destas, preparou-se corpos de prova com $20 \mathrm{~mm} \times 20 \mathrm{~mm} \times 20 \mathrm{~mm}$ e $30 \mathrm{~mm} \times 30 \mathrm{~mm} \times 60 \mathrm{~mm}$ (radial $\times$ tangencial $\times$ longitudinal), os quais foram divididos igualitariamente dentre as propriedades analisadas. Para cada análise realizada utilizou-se 21 amostras, sendo 7 para controle, 7 para amostras com $1 \%$ de sílica impregnada e 7 para amostras com $2 \%$ de sílica. Após as amostras dimensionadas foram encaminhadas a câmara climatizada $\left(20^{\circ} \mathrm{C}\right.$ de temperatura e $65 \%$ de umidade relativa) até sua estabilização dimensional. Os pesos foram determinados através de balança analítica com precisão de $( \pm 0,01 \mathrm{~g})$.

\section{Caracterização da partícula de sílica}

Rendimento de sílica por quantidade de casca de arroz

O rendimento analisado foi a relação do produto obtido (sílica) em relação a matéria prima (casca de arroz). Foram pesadas em cada batelada realizada cerca de 80 gramas de casca de arroz para avaliar o rendimento após a calcinação do material (Equação 1)

$\mathrm{R}=\left(\frac{\mathrm{PO}}{\mathrm{MP}}\right) * 100$

Em que: $\mathrm{R}=$ rendimento (\%); $\mathrm{PO}=$ produto obtido (g); $\mathrm{MP}=$ matéria prima (g).

\section{Espectroscopia no Infravermelho por Transformada de Fourier}

Utilizou-se um dispositivo de refletância total atenuada (ATR) visando verificar possíveis alterações nos grupamentos funcionais da madeira modificada com a sílica e também apenas das partículas de silica. Foi realizada em espectroscópio FT/IR Jasco, modelo 4100, em amostras em pó, efetuando a leitura na região denominada de fingerprint no intervalo de 600 a $2000 \mathrm{~cm}^{-1}$, com resolução de $4 \mathrm{~cm}^{-1}$, velocidade do scanner de $2 \mathrm{~mm} / \mathrm{sec}$ e filtro de $30000 \mathrm{~Hz}$, e espectro final resultante da média de 32 varreduras.

\section{Difração de raios $x$}

A análise de difração de Raio X foi realizada em um difratômetro Philips, modelo X'Pert MPD equipado com monocromador de grafite de tubo com alvo de $\mathrm{Cu}$ de anodo fixo e operado com $40 \mathrm{kV}$ e $40 \mathrm{~mA}$, o comprimento de onda de radiação é $\lambda=0,154056 \mathrm{~nm}$ de Cu-Ka. Os padrões utilizados na análise foram: $\Delta 2 \theta=5-75^{\circ}$, passo $0,05^{\circ}$, tempo por passo de 3 segundos e fendas de $1 / 2^{\circ}$, em temperatura ambiente e amostra de sílica em forma de pó.

\section{Granulometria}

A análise granulométrica foi realizada no equipamento CILAS 1064 Liquid, com alcance de $0.04 \mu \mathrm{m}-500.00 \mu \mathrm{m} / 100$ Classes. Foi utilizado detergente como agente dispersante e índice de medição de 452 (ultrassonografia de 60s).

Após constatado com a análise granulométrica que a metodologia seguida não obteve o tamanho final desejado, a sílica passou por novo processo de moagem e peneiramento. Usou-se peneira de 200 mesh, para reter toda partícula maior que $74 \mu \mathrm{m}$ a fim de homogeneizar a amostra e garantir uma granulometria máxima. 
Para o processo de impregnação foi utilizado uma autoclave horizontal de pequeno porte com sistema de vácuo e pressão (célula cheia). Anterior à impregnação, foi preparada a sílica em meio aquoso, para isso adicionou-se a água destilada (considerou-se a água com $1 \mathrm{~g} / \mathrm{cm}^{2}$ de densidade), $1 \%$ e $2 \%$ de sílica em relação ao peso de água destilada e $0,5 \%$ de hexametafosfato de sódio como dispersante, visando a homogeneização do meio e não decantação da partícula.

Visando retirar o ar do interior da autoclave e da madeira, utilizou-se uma bomba de vácuo durante 30 minutos. Esse processo expande os poros da madeira e retira o ar de seu interior, aumentando a capacidade da partícula de sílica adentrar.

A solução aquosa com a sílica foi colocada na autoclave por meio de diferença de pressão, enchendo totalmente a autoclave. Em seguida, com um compressor aplicou-se pressão de $8 \mathrm{kgf} / \mathrm{cm}^{2}$ durante 120 minutos. Finalizada a impregnação, as amostras foram encaminhadas para estufa laboratorial ajustada a $60^{\circ} \mathrm{C}$ a fim de polimerizar a sílica na madeira. As amostras permaneceram na estufa nessas condições até peso constante, para então serem encaminhas a câmara climatizada a $20^{\circ} \mathrm{C}$ de temperatura e $65 \%$ de umidade relativa, onde após estabilização pesou-se novamente em balança analítica para obtenção de suas massas.

\section{Caracterização de propriedades das madeiras impregnadas com sílica}

\section{Teor de umidade}

Na determinação do teor de umidade adaptou-se a norma ASTM D 2395 (2017), para isso pesou-se as amostras em balança analítica de precisão de $\pm 0,01$, obtendo assim seu peso úmido. Para coletar seu peso absolutamente seco, as amostras foram secas em estufa laboratorial a $103 \pm 2 \mathrm{C}^{\circ}$. Com os dados obtidos, determinou-se o teor de umidade referente a cada amostra (Equação 2).

$\mathrm{Tu}=\left(\frac{\mathrm{M} 1-\mathrm{M} 2}{\mathrm{M} 2}\right) * 100$

Em que: $\mathrm{Tu}=$ teor de umidade das amostras (\%) M1 = massa da amostra úmida (g), M2= massa da amostra após a secagem $\left(103 \pm 2 \mathrm{C}^{\circ}\right)(\mathrm{g})$.

\section{Ganho de massa}

Para a obtenção do percentual de ganho de massa da madeira com a impregnação da sílica, pesou-se as amostras antes e depois do processo de impregnação. Ambas as pesagens após as amostras estarem estabilizadas em câmara climatizada a $20^{\circ} \mathrm{C}$ de temperatura e $65 \%$ de umidade relativa. Com os valores das massas determinou-se o percentual de ganho de massa (Equação 3).

$$
\mathrm{PMG}=\frac{(\mathrm{Mb}-\mathrm{Ma})}{\mathrm{Ma}} * 100
$$

Em que: $\mathrm{PGM}=$ percentual de ganho de massa (\%), Mb= massa da amostra após a impregnação (g), Ma = massa da amostra antes da impregnação (g).

\section{Massa específica básica ( $\rho b)$ e aparente ( 1212}

Para determinar a massa específica aparente a 12\% (Equação 4), as madeiras já estabilizadas foram pesadas em balança analítica com precisão de $\pm 0,01 \mathrm{~g}$, para obtenção de sua massa. Seus volumes foram obtidos através de paquímetro digital. 
Já para a massa específica básica foi adaptado a norma da American Society for Testing and Materials D 2395 (ASTM, 2017) onde as amostras foram saturadas utilizando vácuo em um dessecador e seu volume determinado através do método do empuxo. As amostras secas em estufa a $103 \pm 2^{\circ} \mathrm{C}$ até remoção total de umidade foram pesadas com balança de precisão (Equação 5).

$\rho 12 \%=\frac{\mathrm{M} 12 \%}{\mathrm{~V} 12 \%}$

$\rho b=\frac{M 0}{V s}$

Em que: $\rho b=$ massa específica básica dos corpos de prova $\left(\mathrm{g} / \mathrm{cm}^{3}\right) ; \rho 12=$ massa específica aparente $12 \%\left(\mathrm{~g} / \mathrm{cm}^{3}\right) ; \mathrm{M} 0=$ massa da amostra seca em estufa à $103^{\circ} \mathrm{C} \mathrm{em} \mathrm{g;} \mathrm{M} 12 \%=$ massa da amostra á $12 \%$ de umidade (g); VS= volume da amostra em condição saturada de umidade $\left(\mathrm{cm}^{3}\right) ; \mathrm{V} 12 \%=$ volume da amostra a $12 \%$ de umidade.

Absorção e taxa de absorção de água

Para a análise de absorção e taxa de absorção de água foram utilizadas 7 amostras como controle, 7 com $1 \%$ de sílica e 7 com $2 \%$ de sílica. Após a estabilização dos corpos de prova em câmara climatizada $\left(20^{\circ} \mathrm{C}\right.$ de temperatura e $65 \%$ de umidade relativa), conferiu-se a estabilidade dimensional com paquímetro digital e a massa com balança analítica.

Previamente à imersão em água foi realizada a pesagem das amostras com aproximadamente $12 \%$ de teor de umidade. Com as amostras já submersas pesou-se a cada 60 minutos nas primeiras 8 horas e após este período a cada 12 horas, até a madeira estar saturada (não variando mais seu peso). Colocou-se então as amostras em estufa a $103 \pm 2^{\circ} \mathrm{C}$ a fim de obter seu peso totalmente seco. Após tomadas as massas das amostras ao longo do estudo, determinou-se a absorção de água na madeira (Equação 6), e a taxa de absorção de água (Equação 7).

$\mathrm{AA}=\frac{\mathrm{Mu}-\mathrm{Mo}}{\mathrm{Mo}} * 100$

$\mathrm{TAA}=\frac{\mathrm{Mu}-\mathrm{Mo}}{\Delta \mathrm{T}} * 100$

Em que: $\mathrm{AA}=$ absorção de água (\%); TAA= taxa de absorção de água $\left(\mathrm{gh}^{-1}\right) ; \mathrm{M0}=$ massa da amostra seca em estufa a $103 \pm 2{ }^{\circ} \mathrm{C}(\mathrm{g}) ; \mathrm{MU}=$ massa da amostra em condição saturada (g); $\Delta \mathrm{t}=$ variação do tempo de imersão dos corpos de prova $(\mathrm{h})$.

\section{Propagação de chamas}

No teste para analisar a retardação de chamas na madeira foi utilizado corpos de prova cúbicos com $20 \times 20 \times 20 \mathrm{~mm}$. Aplicou-se fogo através do bico de Bunsen (utilizando gás butano), mantendo a distância de 10 centímetros do fogo a madeira, de acordo com análise realizada por Tondi et al., (2012). Foi acompanhado a perda de massa nas amostras em balança analítica até atingirem $20 \%$ de sua massa inicial, registrando através de imagens o teste para melhor ilustração dos dados.

\section{Análise estatística}

Para a realização das análises estatísticas adotou-se o método de LSD Fisher com 5\% de probabilidade de erro. Para isso, foi utilizado o software Statgraphics Centurion que calcula 
as análises requeridas comparando os resultados obtidos intragrupos e entre os grupos, determinando se há relevância estatisticamente significativa nos resultados.

\section{RESULTADOS E DISCUSSÃO}

Obteve-se valor médio de rendimento de sílica de $25 \%$ com variação máxima de $\pm 2 \%$. Com base em Della et al., (2001) utilizando métodos semelhantes para extração da sílica, deste percentual encontrado cerca de $96,65 \%$ é efetivamente $\mathrm{SiO}_{2}$, tendo como principais impurezas (em quantidades inferiores a 1\%) $\mathrm{K}_{2} \mathrm{O}, \mathrm{CaO}, \mathrm{Al}_{2} \mathrm{O}_{3}, \mathrm{MgO}$ e $\mathrm{P}_{2} \mathrm{O}_{5}$, estes óxidos são considerados fundentes e formadores de fase vítrea.

Com a análise granulométrica contatou-se que havia grande variação no tamanho das partículas dentro da amostra de sílica. Cerca de $50 \%$ das partículas estavam próximas ao diâmetro de $89.63 \mu \mathrm{m}, 40 \%$ delas próximas ao de $211.35 \mu \mathrm{m}, 8 \%$ com diâmetro em $24.65 \mu \mathrm{m}$ e cerca de apenas $2 \%$ com diâmetro menor que $5 \pm 2 \mu$ m (Figura 1).

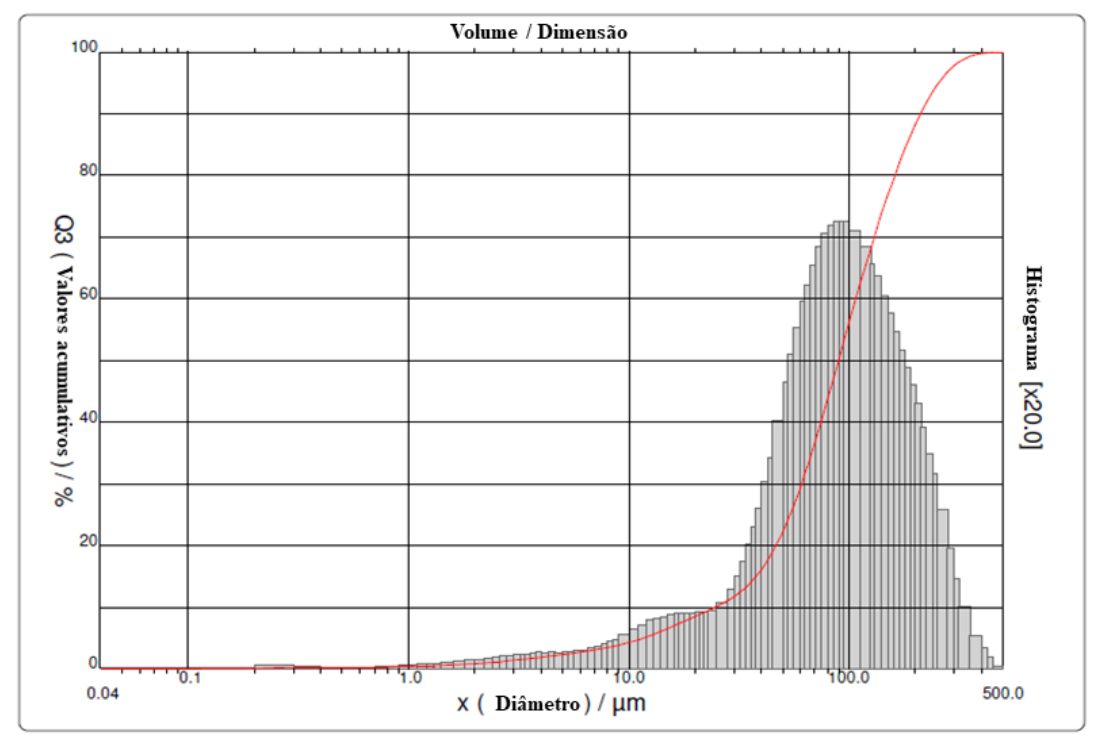

Figura 1: A análise granulométrica da casca de arroz após tratamentos químicos e físicos, com alcance de $0.04 \mu \mathrm{m}-500.00 \mu \mathrm{m} / 100$ Classes.

Esses resultados vão ao encontro tanto no tamanho do diâmetro, quanto na dispersão dos tamanhos com o trabalho de Della et al. (2001), onde analisaram a granulometria da sílica extraída da casca do arroz com métodos similares, com tratamento químicos e térmicos.

Devido a essa dispersão no tamanho das partículas, foi realizado o processo de peneiração para homogeneização do tamanho. Com isso, todas as partículas maiores que $74 \mu \mathrm{m}$ foram removidas. Esse processo se fez necessário, visto que os poros da madeira de Pinus elliottii possuem em média $5 \mu \mathrm{m}$ de diâmetro (De Muñiz \& Inés, 1993) e para que não houvesse decantação imediata das partículas devido ao seu tamanho elevado. As partículas que possuíam tamanho muito superior, caso não decantassem, poderiam realizar uma barreira física impedindo a penetração de partículas menores.

A Espectroscopia no Infravermelho por Transformada de Fourier permite a análise qualitativa de compostos devido aos modos característicos de vibração de cada grupo pois provocam o aparecimento de bandas específicas, assim, geralmente contém mais informações do que os valores de posição ou de absorção de alguns picos, atuando como uma impressão digital de uma dada amostra (Ruschel et al., 2014). De acordo com a intensidade de absorção das bandas é possível dizer se houve ou não concentração de partículas. Analisou-se a partícula de sílica, a madeira controle e também a madeira tratada (Figura 2). 


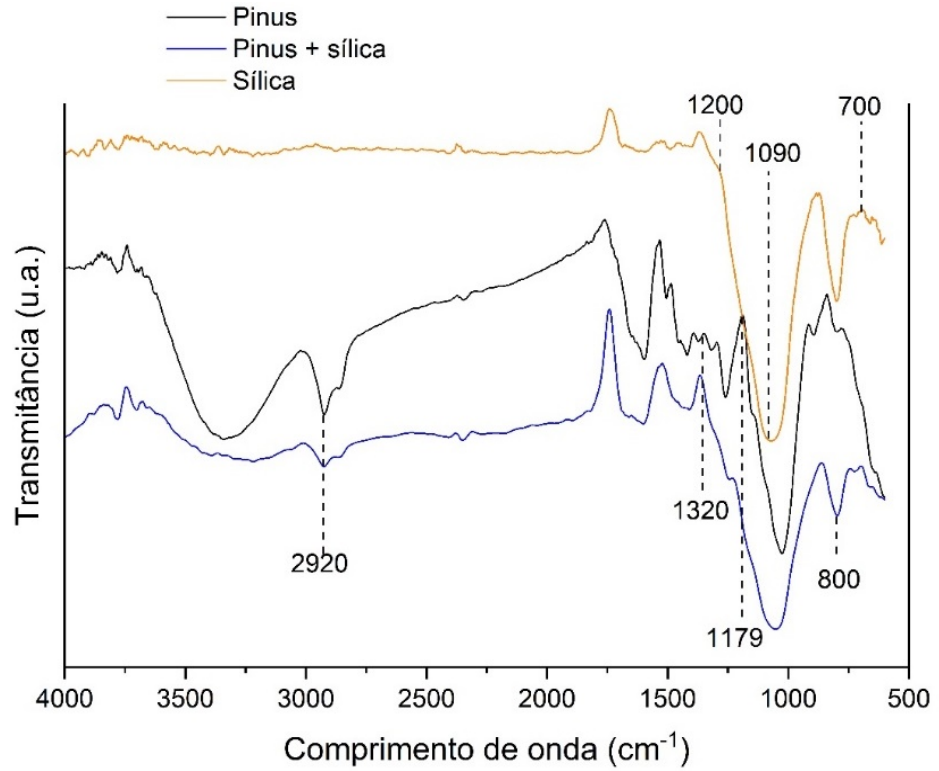

Figura 2: Espectroscopia no Infravermelho por Transformada de Fourier da madeira controle, da partícula de sílica e da madeira impregnada com sílica.

Referente aos espectros de infravermelho das partículas de sílica, os picos de absorção do SI-O-SI foram atribuídos na banda de $1090 \mathrm{~cm}^{-1}$ e ainda, nas bandas de 1200 e $700 \mathrm{~cm}^{-1}$ são atribuídos a modos de vibração da rede de sílica (Tabela 1). Observa-se que ocorreu nestes pontos um deslocamento das bandas, quando comparado a madeira controle com a madeira impregnada com sílica.

Tabela 1: Caracterização de bandas e componentes químicos de madeira por espectroscopia de Infravermelho.

\begin{tabular}{|c|c|c|}
\hline Comprimento de onda $\left(\mathrm{cm}^{-1}\right)$ & Atribuiç̧ão & Referência \\
\hline $700-1090-1200$ & $\begin{array}{l}\text { Modos de vibração da rede de } \\
\text { sílica. }\end{array}$ & Salavati-Niasari et al. (2013) \\
\hline 800 & $\begin{array}{l}\text { Anel de benzeno substituído } \\
\text { em lignina de madeira mole }\end{array}$ & Kuo et al. (2007) \\
\hline 1179 & $\begin{array}{l}\text { Faixa assimétrica C-O-C em } \\
\text { celulose e hemicelulose }\end{array}$ & Kuo et al. (2007) \\
\hline 1320 & $\begin{array}{l}\text { Vibração de rocha } \mathrm{CH} 2- \\
\text { Celulose }\end{array}$ & Sun et al. (2015) \\
\hline 2920 & $\begin{array}{l}\text { Estiramento dos grupos } \\
\text { metílicos - Celulose }\end{array}$ & Poletto et al. (2012) \\
\hline
\end{tabular}

A banda em torno de $800 \mathrm{~cm}^{-1}$, caracteriza alterações no anel de benzeno substituído em lignina, pode-se notar uma alteração significativa, já a banda de $1320 \mathrm{~cm}^{-1}$, nota-se um surgimento de um pico mais acentuado para a madeira tratada, isso é caracterizado por maior frequência de ocorrência de ligações nos grupos das celuloses. Nesse contexto, variações nas intensidades e posições dos picos dos espectros indicam mudanças nos grupamentos funcionais e forças de ligações dos componentes no interior da madeira, fato esse corroborado por Zhang et al. (2015). Isso colabora com a provável presença de parte da sílica no interior da madeira e também superficialmente.

Em $800 \mathrm{~cm}^{-1}$ ocorreu um aumento na intensidade da banda da madeira tratada com sílica, comparado com a madeira controle. Nota-se uma semelhança na curva da madeira impregnada, com a curva da partícula de sílica, indicando que há presença de partícula na mesma. 
A banda de $1179 \mathrm{~cm}^{-1}$ da madeira de Pinus elliottii é uma faixa assimétrica C-O-C em celulose e hemicelulose. Pode-se observar uma drástica mudança nesta banda quando comparado com a da madeira impregnada com sílica, com a suavização da curva, percebe-se que diminuiu a faixa assimétrica C-O-C em celulose e hemicelulose com a impregnação. A mudança na banda de $2920 \mathrm{~cm}^{-1}$ relaciona-se ao alongamento de C-H, ou seja, grupos de estiramento metílicos simétricos presentes nos espectros de todos os componentes da madeira, mas principalmente no espectro para a celulose (Poletto et al., 2012). As mudanças atribuídas às bandas da madeira tratada com sílica comprovam a existência de partículas de sílica na madeira.

A análise de DRX é a técnica mais útil para identificação da estrutura química de um elemento, com base no gráfico (Figura 3) gerado a partir dos dados da análise, foi possível confirmar que a partícula possui características amorfas.

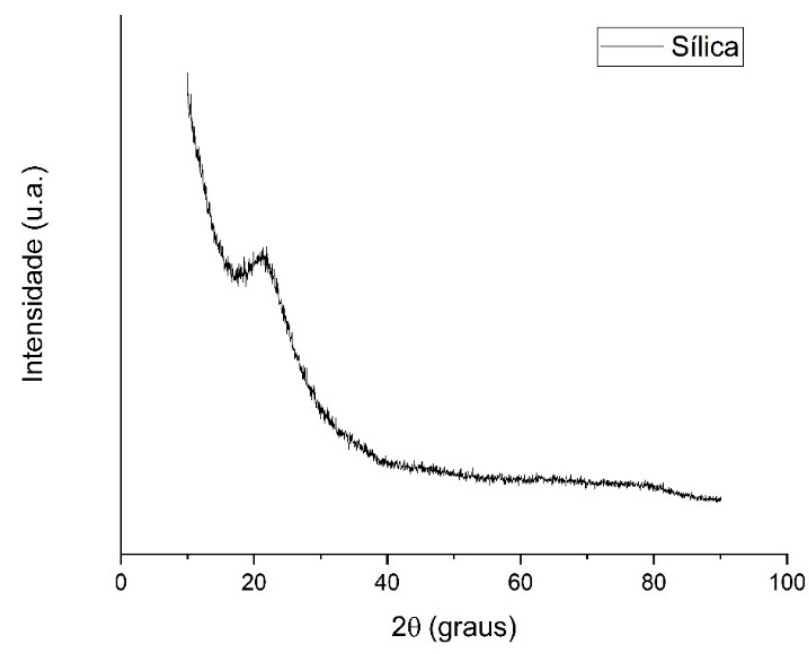

Figura 3: Difração de raios x da casca de arroz após processo químico e calcinação.

Há uma forte amplitude nos picos de nanossílica concentrados na faixa de $22^{\circ}-23^{\circ}(2 \theta)$, que estão de acordo com o forte e amplo pico de uma característica de $\mathrm{SiO}_{2}$ amorfo, confirmada pela ausência de qualquer estrutura cristalina ordenada (Affandi, et al., 2009; Salavati-Niasari, et al. 2013). Corroborando com os resultados obtidos por Thuadaij \& Nuntiya (2008) onde resultados encontrados mostram que a sílica pura está em estado amorfo.

A absorção de água mostrou um comportamento muito similar entre as madeiras na primeira hora, ou então, até atingirem um percentual de $60 \%$ de absorção de água. No período de 2 a 7 horas as madeiras modificadas com sílica absorveram mais água (cerca de $10 \%$ ), isto deve-se às características amorfas das partículas mencionadas anteriormente. Todavia, depois deste período a madeira controle continuou absorvendo água de modo acentuado, enquanto as madeiras impregnadas não. Desta forma, depois da hora 20 o controle absorveu mais água, chegando ao término de 72 horas com $130 \%$ de absorção de água enquanto as madeiras impregnadas com 120\% (Figura 4).

A absorção e a taxa de absorção de água realizadas (Figura 5) confirmam os resultados obtidos na análise de DRX, uma vez que se constatou que a sílica extraída no trabalho possui características amorfas. Partículas amorfas possuem afinidade com a água devido a sua composição química, mais precisamente, a sua estrutura. Normalmente é considerado uma estrutura amorfa como o inverso de estrutura cristalina. 


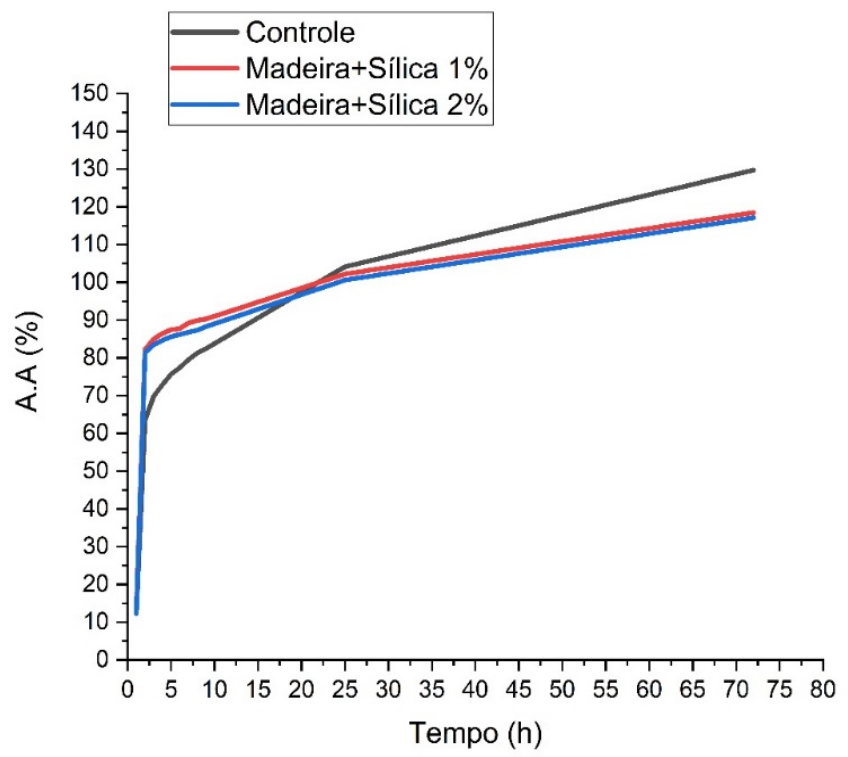

Figura 4: Absorção de água (A.A) de madeira de Pinus elliottii: controle e impregnada com sílica a 1\% e $2 \%$.

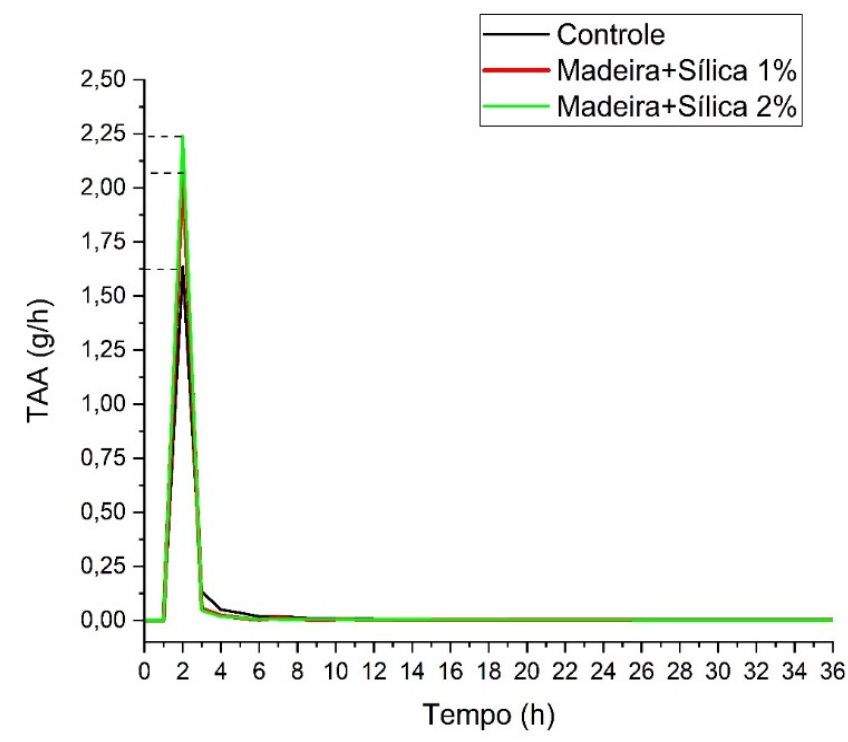

Figura 5: Taxa de absorção de água (TAA) de madeira de Pinus elliottii: controle e impregnada com sílica a $1 \%$ e $2 \%$.

Pode-se explicar a inversão na absorção de água do grupo controle, devido a saturação das partículas de sílica e a troca de componentes com afinidade com a água pela sílica. Ainda, nota-se que o percentual de sílica não demonstrou, nesse contexto, ser um fator de relevância na absorção de água, uma vez que as madeiras com 1\% e 2\% mantiveram o mesmo comportamento. No entanto no que se refere a taxa de absorção de umidade percebe-se que o teor de silica influenciou diretamente. A madeira controle teve uma taxa máxima de aproximadamente 1,6 g/h nas primeiras 3 horas, já a madeira impregnada com $1 \%$ de sílica nas primeiras 3 horas teve uma taxa de 2,1 g/h. A madeira impregnada com $2 \%$ de sílica obteve a maior taxa de absorção de água no mesmo período, aproximadamente $2,24 \mathrm{~g} / \mathrm{h}$. Isto possivelmente ocorreu principalmente pela presença da silica no exterior da madeira. Segundo Ashfaq et al. (2012) citam que o $\mathrm{SiO}_{2}$ tem a capacidade de absorver e adsorver 
umidade com muita facilidade. Sezavar et al. (2019) citam que pela sua grande quantidade de zonas amorfas a sílica possui afinidade com a água.

A impregnação da sílica na madeira demonstrou grande eficiência no teste de propagação de chamas. As amostras impregnadas com 1\% de sílica retardaram a ignição das chamas em torno de 3 vezes e as amostras com 2\% de sílica retardaram 6,7 vezes em relação as madeiras controle. Li et al. (2019) citam que a silica possui boas propriedades térmicas e quando são necessários altos níveis de isolamento térmico em inúmeros materiais a utilização da sílica é uma excelente opção.

O tempo para as amostras atingirem $20 \%$ de sua massa inicial aumentou em 25 minutos para as madeiras tratadas com 1\% e em torno de 49 minutos para as tratadas com 2\% de sílica, acarretando um aumento de 4,7 vezes, em comparação com o grupo controle (Tabela 2). Valores superiores a Sun et al., (2012) onde, para madeiras tratadas com $\mathrm{TiO}_{2} / \mathrm{ZnO}$ o tempo aproximado foi 15 minutos, comparado com o controle de 6,7 minutos, onde também houve melhoria com a utilização de partículas. Cai et al. (2020) mencionam que como isolamento térmico em materias a silica pode inibir efetivamente a condução de calor sólido e gasoso por causa de sua estrutura linear e amorfa podendo resistir até cerca de $800^{\circ} \mathrm{C}$.

Tabela 2: Valores médios do teste de propagação de chamas.

\begin{tabular}{ccc}
\hline Amostra & Tempo até ignição $(\mathbf{m i n})$ & Tempo $\mathbf{2 0 \%}$ da massa $(\mathbf{m i n})$ \\
\hline Controle & $8: 24$ & $13: 36$ \\
$1 \%$ & $24: 32$ & $38: 36$ \\
$2 \%$ & $55: 02$ & $62: 43$ \\
\hline
\end{tabular}

Pode-se observar que a massa específica (12\%) das madeiras analisadas não teve variação estatisticamente significativa (Tabela 3). Nas madeiras impregnadas o não acréscimo da massa específica, deve-se a quantidade baixa de sílica impregnada $1 \%$ e $2 \%$ e ao baixo peso das partículas. Os valores médios obtidos para a massa específica $12 \%$ foram de $0,587,0,564$ e $0,585\left(\mathrm{~g} / \mathrm{cm}^{3}\right)$ para os grupos controle, madeira impregnada com $1 \%$ de sílica (T1\%) e com $2 \%$ de sílica (T2\%) respectivamente. Os valores estão muito próximos aos valores encontrados por Junior \& Lahr (2014) que encontraram 0,56 (g/cm³) para a madeira de Pinus elliottii.

Tabela 3: Valores médios e resumo estatístico referente a massa específica aparente ( $\rho 12)$, massa específica básica $(\rho b)$, teor de umidade e ganho de massa da madeira de Pinus elliottii impregnada com sílica e do grupo controle.

\begin{tabular}{|c|c|c|c|c|}
\hline Tratamento & $\rho 12\left(\mathrm{~g} / \mathrm{cm}^{3}\right)$ & $\rho b\left(g / \mathrm{cm}^{3}\right)$ & $\begin{array}{c}\text { Teor de umidade } \\
\text { (\%) }\end{array}$ & $\begin{array}{c}\text { Ganho de massa } \\
(\%)\end{array}$ \\
\hline Controle & $0,587 a^{( \pm 0,022)}$ & $0,451^{( \pm 0,129)}$ & $11,69 a^{( \pm 0,136)}$ & - \\
\hline $\mathrm{T} 1 \%$ & $0,564 a^{( \pm 0,051)}$ & $0,443^{( \pm 0,188)}$ & $12,79 a^{( \pm 1,930)}$ & $4,58 \mathrm{a}^{( \pm 1,936)}$ \\
\hline $\mathrm{T} 2 \%$ & $0,585 a^{( \pm 0,036)}$ & $0,482( \pm 0,197)$ & $11,27 a^{( \pm 0,316)}$ & $3,35 a^{( \pm 0,719)}$ \\
\hline $\mathrm{CV}$ & $6,758 \%$ & $4,856 \%$ & $10,58 \%$ & $38,83 \%$ \\
\hline $\mathrm{DP}$ & $\pm 0,039$ & $\pm 0,121$ & $\pm 1,26$ & $\pm 1,54$ \\
\hline $\mathrm{F}$ & $1,05 \mathrm{~ns}$ & $1,48 \mathrm{~ns}$ & $3,41 \mathrm{~ns}$ & $2,45 \mathrm{~ns}$ \\
\hline
\end{tabular}

Em que: valores entre parênteses sobrescritos as médias representam o desvio padrão do tratamento e letras diferentes, nas colunas, indicam diferenças significativas conforme o teste LSD Fisher, em 5\% de probabilidade de erro; CV (\%) - coeficiente de variação dos tratamentos; DP - desvio padrão dos tratamentos; * - apresenta diferença significativa pelo teste $F(p<0,05)$; ns - não apresenta diferença significativa pelo teste $F(p \geq 0,05)$.

A massa específica básica obteve valores médios de 0,451 g/cm³ para o grupo controle, valor abaixo de Serpa et al. (2003) onde para a madeira de Pinus elliottii obteve valor próximo a $0,5 \mathrm{~g} / \mathrm{cm}^{3}$. As madeiras tratadas não variaram significativamente o valor de sua massa específica básica. O ganho de massa obteve valores médio de 4,57\% para o tratamento com 
$1 \%$ de sílica e 3,35\% para o com $2 \%$ de sílica. Esses valores demostram que houve ganho de massa na madeira devido a impregnação, contudo, os dados não apresentaram diferença estatística, quando comparados.

\section{CONCLUSÃO}

O método empregado para a extração da sílica a partir da casca de arroz se mostrou eficiente, contudo, para a impregnação na madeira foi necessário a melhoria do tamanho final da partícula, por meio de peneiração.

A análise de difração de raio $x$, mostrou a estrutura química da sílica obtida, a qual se apresentou com característica de material amorfo. A Espectroscopia no Infravermelho por Transformada de Fourier demonstrou-se eficaz para a comprovação do fato das partículas de sílica terem impregnado na madeira.

A taxa de absorção de água foi maior para as madeiras tratadas, onde a porcentagem de sílica no processo de impregnação não demonstrou influência significativa sobre essas características. Se obteve um comportamento semelhante, com maior absorção de água nas primeiras horas das madeiras impregnadas, contudo, após as partículas saturarem de água, ocorreu a inversão na absorção. Assim, ao final da análise as amostras tratatas absorveram menos água que o grupo controle. A fim de melhorar essa propriedade, cabe futuras pesquisas visando a adição de algum elemento a sílica de modo a aumentar a impermeabilização das madeiras tratadas.

O teste de propagação de chamas foi o de maior destaque nas características da madeira. As madeiras impregnadas demonstraram grande dificuldade de propagar fogo, demorando para que houvesse a ignição e perda de massa nas amostras. Ambas as porcentagens de tratamento obtiveram tais ganhos, onde, conforme aumento da carga de sílica na madeira, melhores os resultados obtidos.

\section{REFERÊNCIAS BIBLIOGRÁFICAS}

Acosta, A., Gallio, E., Schulz, H. R., Zanatta, P., Barbosa, K. T., De Avila Delucis, R., \& Gatto, D. A. (2020). Wood polymer composites produced by in situ polymerization of styrene into juvenile and mature pine woods. International Wood Products Journal, 11(4), 204-210. http://dx.doi.org/10.1080/20426445.2020.1776486.

Affandi, S., Setyawan, H., Winardi, S., Purwanto, A., \& Balgis, R. (2009). A facile method for production of high-purity silica xerogels from bagasse ash. Advanced Powder Technology, 20(5), 468-472. http://dx.doi.org/10.1016/j.apt.2009.03.008.

Ashfaq, M., Tabassum, R., Ahmed, M. M., Mehmood, K., Asghar, M., \& Hussain, T. (2012). Improved method for preparation of anhydrous silica by microwave irradiation with spectroscopic characterization and toxicity assay. Journal of Non-Crystalline Solids, 358(4), 847-853. http://dx.doi.org/10.1016/j.jnoncrysol.ILima.12.078.

ASTM. (2017). ASTM D2395 - 17. Standard Test Methods for Density and Specific Gravity (Relative Density) of Wood and Wood-Based Materials. Recuperado em 10 de agosto de 2019, de https://www.astm.org/Standards/D2395.htm.

Ayrilmis, N., \& Kaymakci, A. (2013). fast growing biomass as reinforcing filler in thermoplastic composites: paulownia elongata wood. Industrial Crops and Products, 43, 457-464. http://dx.doi.org/10.1016/j.indcrop.2012.07.050.

Cademartori, P. H., Gatto, D. A., Stangerlin, D. M., Schneid, E., \& Hamm, L. G. (2012). Qualidade da madeira serrada de Pinus elliottii Engelm. procedente de florestas resinadas. Cerne, 18, 4. https://doi.org/10.1590/S0104-77602012000400007.

Cai, H., Jiang, Y., Feng, J., Zhang, S., Peng, F., Xiao, Y., \& Feng, J. (2020). Preparation of silica aerogels with high temperature resistance and low thermal conductivity by monodispersed silica sol. Materials \& Design, 108640, 108640. http://dx.doi.org/10.1016/j.matdes.2020.108640.

De Muñiz, B., \& Inés, G. (1993). Caracterização e desenvolvimento de modelos para estimar as propriedades e o comportamento na secagem da madeira de Pinus elliottii Engelm. e Pinus taeda L. (Tese de doutorado). Universidade Federal do Paraná, Paraná, p. 252. 
Della, V. P., Kuhn, I., \& Hotza, D. (2001). Caracterização de cinza de casca de arroz para uso como matéria-prima na fabricação de refratários de sílica. Quimica Nova, 24(6), 778-782. http://dx.doi.org/10.1590/S0100-40422001000600013.

Fernandes, L., Sabino, M. G., \& Rossetto, H. L. (2014). Método de extração de sílica da casca do arroz. Cerâmica, 60(353), 160-163. http://dx.doi.org/10.1590/S0366-69132014000100022.

Götze, J., Möckel, R., Langhof, N., Hengst, M., \& Klinger, M. (2008). Silicification of wood in the laboratory. Ceramics Silikaty, 52(4), 268-277.

Junior, G. B., \& Lahr, F. A. R. (2014). Aplicação da madeira de Pinus na construção civil. Madeira: arquitetura e engenharia, 1(2), 13-18.

Kuo, M., McClelland, J. F., Luo, S., Chien, P.-L., Walker, R. D. Hse, C.-Y. (2007). Applications of infrared photoacoustic spectroscopy for wood samples. Wood and Fiber Science, 20(1), 132-145.

Li, D., Zhang, C., Li, Q., Liu, C., Arici, M., \& Wu, Y. (2019). Thermal performance evaluation of glass window combining silica aerogels and phase change materials for cold climate of China. Applied Thermal Engineering, 165, 114-547. http://dx.doi.org/10.1016/j.applthermaleng.2019.114547.

Nicacio, M. A. (2017). Efeito de biopartículas de sílica obtidas de casca de arroz no tratamento da madeira de Pinus elliottii (Dissertação de mestrado). Universidade Federal do Espírito Santo, Espirito Santo.

Poletto, M., Zattera, A. J., \& Santana, R. M. C. (2012). Structural differences between wood species: evidence from chemical composition, FTIR spectroscopy, and thermogravimetric analysis. Journal of Applied Polymer Science, 126(S1), E337-E344. http://dx.doi.org/10.1002/app.36991.

Rowell, R. (2012). Chemical modification of wood to produce stable and durable composites. Cellulose Chemistry and Technology, 46(7-8), 443-448.

Ruschel, C. F. C., et al (2014). Análise exploratoria aplicada a espectros de reflexão total atenuada no infravermelho com transformada de Fourier (ATR-FTIR) de blendas de biodiesel/diesel. Quimica Nova, 37(5), 810-815.

Salavati-Niasari, M., Javidi, J., \& Dadkhah, M. (2013). Ball milling synthesis of silica nanoparticle from rice husk ash for drug delivery application. Combinatorial Chemistry \& High Throughput Screening, 16(6), 458-462. PMid:22931308. http://dx.doi.org/10.2174/1386207311316060006.

Serpa, P. N., Vital, B. R., Della Lucia, R. M., \& Pimenta, A. S. (2003). Evaluation of some properties of Eucalyptus grandis, Eucalyptus saligna and Pinus elliottii. Revista Árvore, 27(5), 723-733. http://dx.doi.org/10.1590/S0100-67622003000500015.

Sezavar, R., Shafabakhsh, G., \& Mirabdolazimi, S. M. (2019). New model of moisture susceptibility of nano silica-modified asphalt concrete using GMDH algorithm. Construction \& Building Materials, 211, 528-538. http://dx.doi.org/10.1016/j.conbuildmat.2019.03.114.

Sun, B., Huang, A., Wang, Y., \& Liu, J. (2015). Natural bamboo (Neosinocalamus affinis Keng) fiber identification using FT-IR and 2D-IR correlation spectroscopy. Journal of Natural Fibers, 12(1), 1-11. http://dx.doi.org/10.1080/15440478.2013.796907.

Sun, Q. F., Lu, Y., Xia, Y. Z., Yang, D. J., Li, J., \& Liu, Y. X. (2012). Flame retardancy of wood treated by TiO2/ZnO coating. Surface Engineering, 28(8), 555-559. http://dx.doi.org/10.1179/1743294412Y.0000000027.

Thuadaij, N., \& Nuntiya, A. (2008). Synthesis and characterization of nanosilica from rice husk ash prepared by precipitation method. J. Nat. Sci. Special Issue on Nanotechnology, 7(1), 59-65.

Tondi, G., Wieland, S., Wimmer, T., Thevenon, M. F., Pizzi, A., \& Petutschnigg, A. (2012). Tannin-boron preservatives for wood buildings: mechanical and fire properties. European Journal of Wood and Wood Products, 70(5), 689-696. http://dx.doi.org/10.1007/s00107-012-0603-1.

Zhang, X., Wang, F., \& Keer, L. M. (2015). Influence of surface modification on the microstructure and thermo-mechanical properties of bamboo fibers. Materials (Basel), 8(10), 6597-6608. PMid:28793585. http://dx.doi.org/10.3390/ma8105327.

Contribuição dos Autores: PRJ: Conceituação, Metodologia, Escrita - Primeira Redação; APC: Escrita - Primeira Redação, Análise Formal, Escrita - Revisão e Edição; HRS: Metodologia, Escrita - Primeira Redação, Escrita Revisão e Edição; EG: Supervisão, Escrita - Primeira Redação, Análise Formal; DAG: Supervisão. 